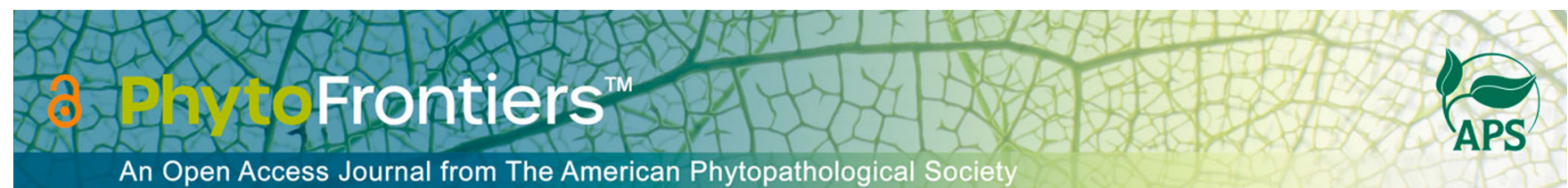

\title{
Research
}

\section{The Diversification of Downy Mildew Species Was Not Driven by the Loss of Mycorrhizal Associations or the Evolution of $\mathrm{C}_{4}$ Photosynthesis}

\author{
William J. Davis ${ }^{1,2}$ (i) | Jo Anne Crouch $^{1,+}$ |
}

1 United States Department of Agriculture, Agricultural Research Service (USDA-ARS), Mycology and Nematology Genetic Diversity and Biology Laboratory, Beltsville, MD 20705

2 Oak Ridge Institute for Science and Education, ARS Research Participation Program, Oak Ridge, TN 37830

† Corresponding author: J. A. Crouch; joanne.crouch@usda.gov

Accepted for publication 30 August 2021

\section{Funding}

This research was supported by funding from USDA-APHIS and USDA-ARS and by an appointment of William J. Davis to the ARS Research Participation Program administered by the Oak Ridge Institute for Science and Education (ORISE) through an interagency agreement between the U.S. Department of Energy (DOE) and U.S. Department of Agriculture (USDA). ORISE is managed by ORAU under DOE contract number DE579AC05-06OR23100.

$e$-Xtra: Supplementary materials are available online.

The author(s) declare no conflict of interest.

\begin{abstract}
There are approximately 700 obligate biotrophic species grouped into 20 genera (Oomycota, Peronosporaceae) that cause downy mildew diseases. In 2001, Dick hypothesized that diversification of downy mildew species was driven in part by host plant secondary metabolites. Dick further speculated that this was driven by the transition of host plants away from mycorrhizal associations or the evolution of $\mathrm{C}_{4}$ photosynthesis. Specifically, loss of mycorrhizal associations or the use of $\mathrm{C}_{4}$ photosynthesis would result in more free carbon that the plants could then use to produce more secondary metabolites. If true, then there should be more downy mildew species that infect hosts from plant lineages that lack mycorrhizal associations or use $\mathrm{C}_{4}$ photosynthesis. However, analysis of 677 downy mildew species for host plant mycorrhizal associations and host plant photosynthetic pathway type shows that this is not what occurred. Seventy percent of downy mildew species parasitize hosts that form mycorrhizal associations, and $94 \%$ of downy mildew species parasitize hosts that use $C_{3}$ photosynthesis. From this, it is concluded that the diversification of downy mildew species was not driven by the loss of mycorrhizal associations or the evolution of $\mathrm{C}_{4}$ photosynthesis. However, $85 \%$ of downy mildew species that parasitize Poaceae (grasses) parasitize $\mathrm{C}_{4}$ hosts. Thus, it is possible that $\mathrm{C}_{4}$ photosynthesis plays a role in the diversification of these genera.
\end{abstract}

Keywords: biodiversity, graminicolous downy mildews, Hyaloperonospora, Peronospora, Peronosclerospora, Plasmopara, Sclerophthora, Sclerospora

Downy mildew diseases are caused by $\sim 700$ obligate biotrophic species grouped into 20 oomycete genera within the Peronosporaceae, often referred to collectively as downy mildews (Thines and Choi 2016). Downy mildew genera are nested within the genus Phytophthora and represent at least two evolutionary transitions from hemitrophy to obligate biotrophy (Bourret et al. 2018; Fletcher et al. 2019; McCarthy and Fitzpatrick 2017; Thines and Choi 2016). Thus, Phytophthora and the downy mildews represent a unique opportunity to study the molecular underpinnings of trophic shifts and the convergence of traits. Furthermore, the diversity within the downy mildew genera seems 
to be driven by host jumps and radiation rather than strict cophylogenetic evolution (Dick 2001; Thines 2014; Thines and Choi 2016). Therefore, the diversity within downy mildew genera also offers a unique opportunity to study the molecular underpinnings of host jumps and the selective forces that lead to host specificity and speciation. This is particularly true for species of Peronosclerospora that parasitize maize because maize is not predicted to be the natural host of these species (Shaw 1975; Thines 2014). However, the relationships among and within the genera remain unresolved owing to low taxon sampling and low sampling of loci (Thines and Choi 2016), which hampers investigations into the evolution of traits and lifestyles.

Even in the absence of resolved relationships, there are hypotheses about the evolution of downy mildew species that can be evaluated. For example, Dick (2001) hypothesized that the radiation of downy mildew species would be facilitated/driven by the secondary metabolism of their host plants and listed a variety of correlations as evidence in support of this hypothesis. As part of his hypothesis, Dick (2001) speculated that host plant species lacking mycorrhizal associations have more carbon to produce secondary metabolites, which in turn makes such host plant species attractive from the perspective of a downy mildew species. If true, then one would expect there to be more downy mildew species on host plants that lack mycorrhizal associations than on host plants that form mycorrhizal associations. Dick (2001) expected this to be particularly true for species of Peronospora and Hyaloperonospora due to their diversity on plant species in Caryophyllaceae and Brassicales, respectively. However, Dick (2001) did not formally test these hypotheses, nor have later authors.

Approximately $90 \%$ of plant families form mycorrhizal associations, which aid the host in water and nutrient acquisition. There are four main types of mycorrhizas: arbuscular mycorrhizas, ectomycorrhizas, ericoid mycorrhizas, and orchid mycorrhizas (Brundrett and Tedersoo 2018). Approximately $72 \%$ of flowering plant species form associations with arbuscular mycorrhizas, and it is believed that these associations evolved early in the history of land plants (Brundrett and Tedersoo 2018). In fact, it is generally thought that nonmycorrhizal plant lineages are an evolutionary loss of the arbuscular mycorrhizal association (Brundrett and Tedersoo 2018). This hypothesis is supported by the presence of genes necessary for the formation of arbuscular mycorrhizal associations in some nonmycorrhizal plants (Ried et al. 2019).

Dick (2001) also speculated that host plants that use $\mathrm{C}_{4}$ photosynthesis would be favored by downy mildew species for the same reason that downy mildew species might favor nonmycorrhizal hosts (i.e., increased carbon for secondary metabolite production). Spencer and Dick (2002) further hypothesized that this relationship would be most prominent with species that cause downy mildews on plant hosts in Poaceae (i.e., grasses). There have been at least 61 independent evolutions of $\mathrm{C}_{4}$ photosynthesis (Sage 2016). The largest number of $\mathrm{C}_{4}$ species $(5,044)$ is within the Poaceae (Sage 2016). In comparison, there are 1,777 eudicot species that use the $\mathrm{C}_{4}$ photosynthetic pathway, with the greatest numbers in Amaranthaceae s.1. (815 species) and Euphorbiaceae (350 species; Sage 2016). In general, plant species that use $\mathrm{C}_{4}$ photosynthesis are better adapted to warm climates (Sage 2016). As with the hypothesized relationship between mycorrhizal status, secondary metabolism, and diversification of downy mildew species, the hypothesized relationship between the evolution of $\mathrm{C}_{4}$ photosynthesis and the diversification of downy mildew species has not been tested.

Herein, the hypotheses that (i) the lack of mycorrhizal associations would facilitate the diversification of downy mildew species and (ii) the $\mathrm{C}_{4}$ photosynthesis pathway would facilitate diversification of downy mildew species were evaluated. It was predicted that if these hypotheses were true, then (i) there would be a greater number of downy mildew species on nonmycorrhizal host plant species than on mycorrhizal host plant species and that (ii) there would be a greater number of downy mildew species on $\mathrm{C}_{4}$ host plant species than on $\mathrm{C}_{3}$ host plant species.

\section{METHODS}

A list of downy mildew species and their type host plant species was generated through an intensive literature search. Species names of both the pathogen and the host were hand-coded into an Excel spreadsheet using monographic works (Barretto and Dick 1991; Constantinescu 1989, 1991, 1992, 1998, 2004; Constantinescu and Fatehi 2002; Constantinescu et al. 2005; Voglmayr et al. 2014a; Waterhouse 1964; Waterhouse and Brothers 1981), Index Fungorum (http://www.indexfungorum.org/), the original descriptions, and later descriptions (see Supplementary References). For species described prior to 1958 that had multiple hosts listed in the description and have not since been lectotypified (e.g., Peronospora aestivalis; Constantinescu 1991), the first host species listed (e.g., Medicago sativa; Constantinescu 1991) was used as the type host species. Analyses were restricted to the type host/a single host to avoid perpetuating potential errors in identification (e.g., the reports of Sclerophthora cryophila on Heteropogon contortus and Dichanthium annulatum [Farr and Rossman 2021] that are likely Peronosclerospora heteropogonis and Peronosclerospora dichanthiicola, respectively, which are species described after the initial reports were made) and potential pseudoreplication. Such an approach is justified because most phylogenetically defined downy mildew species have a narrow plant host range with either one host or a few closely related hosts (e.g., Choi et al. 2008, 2009a, 2009b, 2010, 2015, 2020; Cunnington 2006; García-Blázquez et al. 2008; Görg et al. 2017; Petrželová et al. 2017; Rouxel et al. 2014; Runge and Thines 2012; Runge et al. 2011; Thines 2011; Thines and Choi 2016; Voglmayr et al. 2014b). Peronospora species infecting hosts in the Brassicales were considered to be members of Hyaloperonospora, even in the absence of formal transfers, based on the trends observed by Constantinescu and Fahtei (2002), Göker et al. (2003, 2004, 2009a, 2009b), Voglmayr et al. (2014a), and Salgado-Salazar et al. (2020). Yang and Berry (2011), Kadereit et al. (2003, 2010), Riina et al. (2013), and Sage (2016) were consulted to determine what photosynthetic pathway each of the plant hosts used. This information was then manually added to the Excel spreadsheet. The spreadsheet was then imported into $\mathrm{R}$ 4.0.3 ( $\mathrm{R}$ Core Team 2020). Using the packages found in the tidyverse (Wickham et al. 2019), column names were converted to snakecase, extra columns were removed, the columns were reordered, and the mycorrhizal status of the host plant species was coded based on the mycorrhizal status of the host plant family according to Brundrett $(2008,2009)$. For the purposes of this study, no distinction was made between the different kinds of mycorrhizal associations or different forms of $\mathrm{C}_{4}$ photosynthesis. The number of species in each downy mildew genus that infected a plant host with/without mycorrhiza was tabulated. The number of species in each downy mildew genus that infected plant hosts using $\mathrm{C}_{3}$, Crassulacean acid metabolism, or $\mathrm{C}_{4}$ photosynthetic pathways was tabulated. Graphs were generated using ggplot2 (Wickham 2016), RColorBrewer (Neuwirth 2014), and patchwork (Pedersen 2021). Because the data set (i.e., the list of species, typical host plant, photosynthetic pathway, and status of mycorrhizal association) comprises the entire population (i.e., is not a sample), the use of sample-based statistical tests (e.g., chi- 
squared test) is not appropriate because the exact values (rather than estimates) are known, and nothing needs to be inferred (Quinn and Keough 2002). Data, scripts, and output are available on GitHub (https://github.com/wjdavis90/Downy_mildews/tree/ main/DM_evolution).

\section{RESULTS}

The majority of plant hosts infected by downy mildews form mycorrhizal associations, with $70 \%$ of the 677 downy mildew species described from mycorrhizal hosts (Fig. 1). Two generaHyaloperonospora (95 species) and Perofascia (two species) were associated exclusively with nonmycorrhizal hosts. Only two genera had species with mycorrhizal and nonmycorrhizal plant hosts: Peronospora had 277 species on mycorrhizal plant hosts and 104 species on nonmycorrhizal plant hosts. Plasmopara had 118 species on mycorrhizal plant hosts and four species on nonmycorrhizal plant hosts.

The majority of downy mildew species (94\%) infected plant hosts that utilize the $\mathrm{C}_{3}$ photosynthesis pathway (Fig. 2). Peronospora had 367 species on plant hosts that use $\mathrm{C}_{3}$ photosynthesis, one species on a plant host that can switch between $\mathrm{C}_{3}$ and Crassulacean acid metabolism pathways, and 13 species on plant hosts that use $\mathrm{C}_{4}$ photosynthesis. Plasmopara and Hyaloperonospora species were only found on plants that use $C_{3}$ photosynthesis. For downy mildew parasites of Poaceae, 24 of the 28 species were parasites of grasses that use $\mathrm{C}_{4}$ photosynthesis (Fig. 2B). All the species in Baobabopsis, Erapthora, Peronosclerospora, Poakatesthia, and Viennotia were on $\mathrm{C}_{4}$ grasses. Sclerophthora had four species on $\mathrm{C}_{3}$ grasses and two species on $\mathrm{C}_{4}$ grasses. Sclerospora had three species on $\mathrm{C}_{4}$ grasses and one species on a $\mathrm{C}_{3}$ host plant.

\section{DISCUSSION}

Dick (2001) hypothesized that the production of secondary metabolites by host plants facilitated the diversification of downy mildew species. As part of this hypothesis, he speculated that lack of mycorrhizal associations would lead to more available carbon and therefore more secondary metabolites. This in turn would make such plants more favorable as hosts for downy mildew species. If true, this should result in a greater diversification of downy mildew species on plant hosts that lack mycorrhizal associations. However, the observed patterns of species diversity do not support this. More downy mildews were found on host plants that form mycorrhizal associations than on host plants that do not. The two exceptions were the genera Hyloperonospora and Perofascia, in which all species parasitized host plants in Brassicales, which is a nonmycorrhizal order of plants (Brundrett 2008, 2009; Delaux et al. 2014). Because there is less species diversity in Hyaloperonospora than in Peronospora and Plasmopara, it seems unlikely that the diversification was due to the lack of mycorrhizal associations. Thus, it is concluded that downy mildew

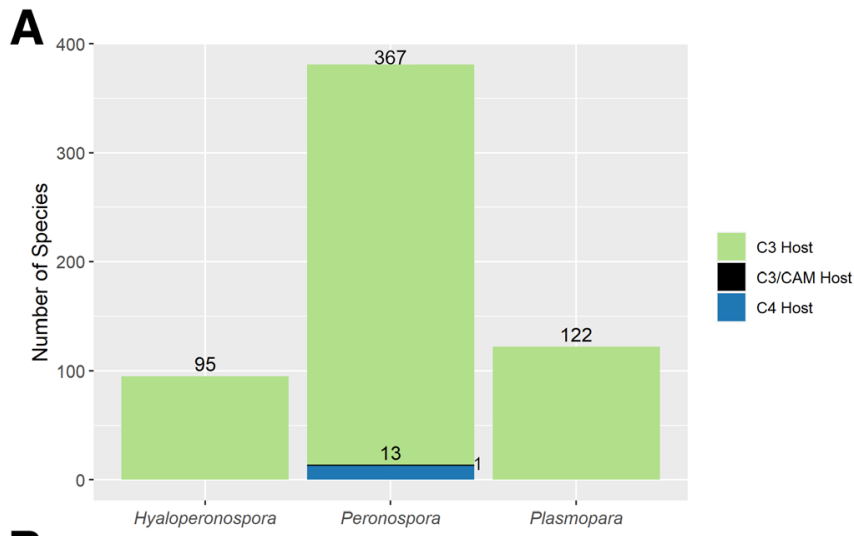

B

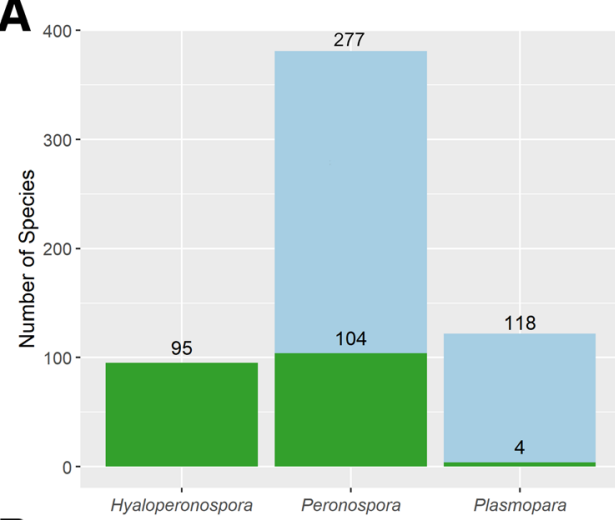

Mycorrhizal Host



B

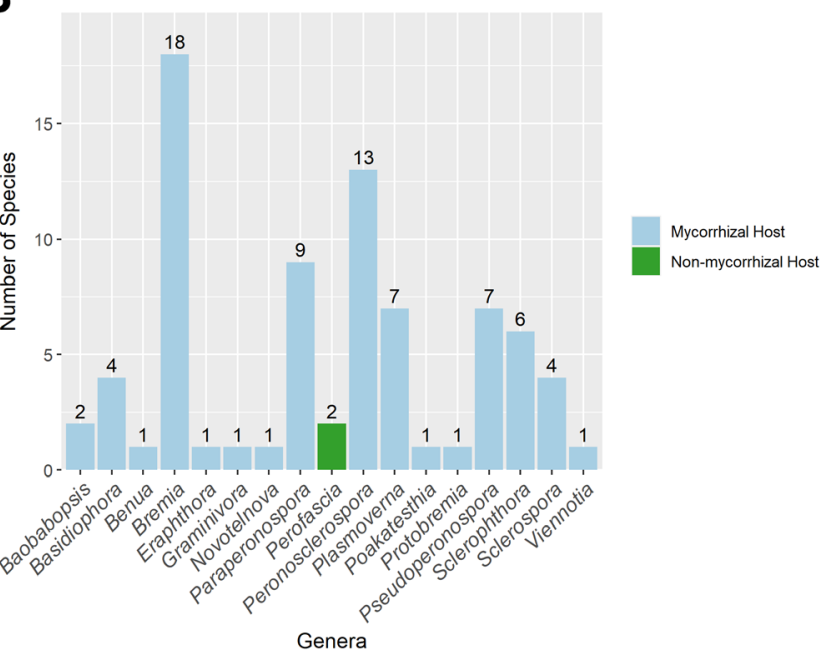

FIGURE 1

Distribution of downy mildew species among mycorrhizal and nonmycorrhizal hosts in the three largest downy mildew genera (A) and in the other 17 genera (B).

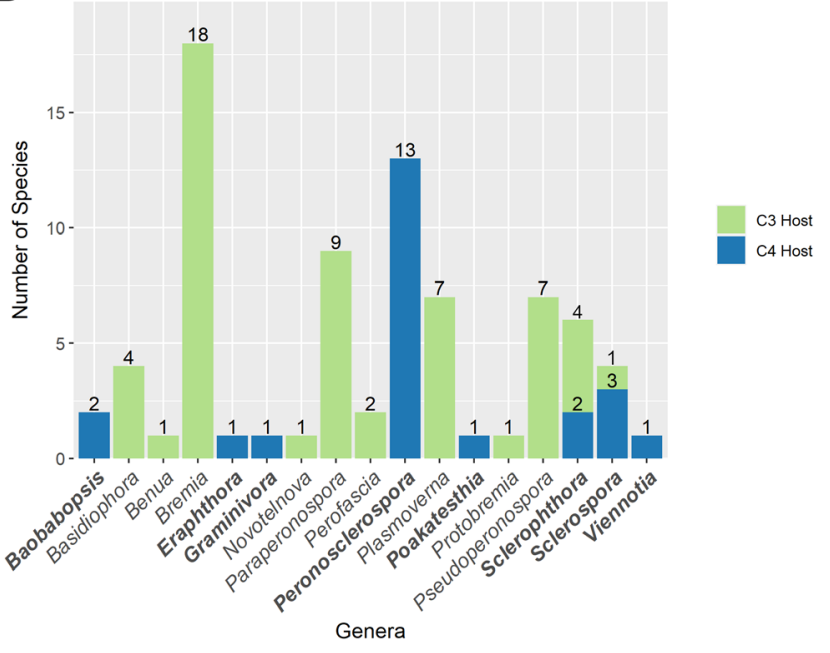

FIGURE 2

Distribution of downy mildew species among $\mathrm{C}_{3}$ and $\mathrm{C}_{4}$ photosynthetic hosts in the three largest downy mildew genera (A) and in the other 17 genera (B). Downy mildew genera that parasitize species of Poaceae (grasses) are in bold. 
species did not evolve to favor host plant species that lack mycorrhizal associations.

The description of additional downy mildew species due to the resolution of known species complexes (e.g., Plasmopara halstedii and $P l$. viticola) will not change the observed patterns of diversity or the above conclusion. The cryptic lineages within these species complexes are associated with closely related plant species, often in the same genus (e.g., Vitis spp.; Rouxel et al. 2013, 2014) or family (e.g., Asteraceae; Rivera et al. 2016). Thus, the plant hosts share the same mycorrhizal or nonmycorrhizal status. The underlying numbers may change, but the observed pattern of a greater number of downy mildew species on mycorrhizal plant hosts will not.

A hypothesis that Dick (2001) did not consider is that the loss of mycorrhizal associations might make it easier for a downy mildew species to jump between distantly related host lineages because of overall lower plant immunity and/or secondary metabolites. The presence of a mycorrhizal association has been found to enhance the host plant's immune system and the production of secondary metabolites (e.g., Avio et al. 2017; Bruisson et al. 2016; Cruz-Silva et al. 2021; Pistelli et al. 2017; Wang et al. 2017). In other words, loss of mycorrhizal associations in some plant lineages might have facilitated host jumps (but not necessarily diversification) because nonmycorrhizal plant species potentially offer a lower barrier to survival if the "wrong" host is encountered. However, this is untestable at present because the direction of host jumps in relation to mycorrhizal status cannot be determined without a sufficiently resolved downy mildew species phylogeny.

Dick (2001) also speculated that the use of $\mathrm{C}_{4}$ photosynthesis would lead to more available carbon and more secondary metabolites, which would make such plants more favorable hosts for downy mildew species. If true, this should result in a greater diversification of downy mildew species on plant hosts that use $\mathrm{C}_{4}$ photosynthesis. However, with $94 \%$ of all downy mildew species associated with plants that use $\mathrm{C}_{3}$ photosynthesis, the observed patterns of species diversity do not support this hypothesis. Thus, it is concluded that downy mildew species did not evolve to favor plant host species that use $\mathrm{C}_{4}$ photosynthesis.

In line with Spencer and Dick's (2002) hypothesis, in downy mildew genera that parasitize Poaceae-Baobabopsis, Erapthora, Peronosclerospora, Poakatesthia, Sclerophthora, Sclerospora, and Viennotia - there were more species that infect grasses that use the $\mathrm{C}_{4}$ pathway ( 24 species) than the $\mathrm{C}_{3}$ pathway (four species). All the species in Baobabopsis, Erapthora, Peronosclerospora, Poakatesthia, and Viennotia infect $\mathrm{C}_{4}$ grasses. All species of Sclerospora that infect grasses are on $\mathrm{C}_{4}$ hosts. Sclerospora magnusiana parasitizes the $\mathrm{C}_{3}$ host Equisetum arvense, but it is a dubious member of the genus (Waterhouse 1964). One notable deviation is the genus Sclerophthora, which contains four species on $\mathrm{C}_{3}$ grasses and two species on $\mathrm{C}_{4}$ grasses.

However, the higher diversity of downy mildew species on $\mathrm{C}_{4}$ grasses than on $\mathrm{C}_{3}$ grasses can be explained by means other than secondary metabolites. One alternative explanation for the observed pattern is sampling bias; specifically, most of the known downy mildew species infect economically important grasses, which are disproportionately $\mathrm{C}_{4}$ species (Sage 2016). Another hypothesis is that $\mathrm{C}_{4}$ grasses are adapted to the same environmental conditions that favor growth of downy mildew species (i.e., warm, moist climates). The data at hand cannot distinguish between Spencer and Dick's (2002) hypothesis and these alternative hypotheses of sampling bias or correlation of favorable environmental conditions. Thus, Spencer and Dick's (2002) hypothesis cannot be accepted or rejected at this time.

The description of additional downy mildew species due to the resolution of known species complexes (e.g., Sclerospora graminicola) will not change the observed patterns of diversity or the above conclusions. The cryptic lineages within these species complexes tend to be on hosts in the same subfamily. Thus, the plant hosts share the same type of photosynthesis pathway. The underlying numbers may change, but the pattern of a greater number of downy mildew species on $\mathrm{C}_{4}$ grasses will not.

The results presented herein do not mean that Dick's (2001) higher hypothesis that secondary metabolites play an important role in the evolution and diversification of downy mildew species is rejected. Rather, what is rejected is the proposed mechanism that lack of mycorrhizal association or use of the $\mathrm{C}_{4}$ photosynthetic pathways increases the production of secondary metabolites and therefore makes certain plant lineages better hosts for downy mildew species. However, it is still possible that the amounts and types of secondary metabolites in a host plant lineage drive evolution and diversification, especially in cases of host jumps (Dick 2001; Thines 2014; Thines and Choi 2016).

In summary, there are more downy mildew species associated with plant hosts that form mycorrhizal associations or $\mathrm{C}_{3}$ plant species than plant hosts that do not form mycorrhizal associations or $\mathrm{C}_{4}$ plant species. Thus, it is concluded that, in general, downy mildew species did not evolve to favor plant host species that lack mycorrhizal associations or that use $\mathrm{C}_{4}$ photosynthesis.

\section{ACKNOWLEDGMENTS}

We appreciate Bryan Vinyard and Matt Kramer for helpful discussions on statistics. We appreciate Bruno Grande, Faye Smith, Lindsay Harrison, and Kevin Amses for their help in navigating R. We appreciate Lindsay Harrison, who helped generate and format the species list. All opinions expressed in this paper are the authors' and do not necessarily reflect the policies and views of USDA, DOE, or ORAU/ORISE. Mention of trade names or commercial products in this publication is solely for the purpose of providing specific information and does not imply recommendation or endorsement by the U.S. Department of Agriculture. The USDA is an equal opportunity provider and employer.

\section{LITERATURE CITED}

Avio, L., Sbrana, C., Giovannetti, M., and Frassinetti, S. 2017. Arbuscular mycorrhizal fungi affect total phenolics content and antioxidant activity in leaves of oak leaf lettuce varieties. Sci. Hortic. 224:265-271.

Barreto, R. W., and Dick, M. W. 1991. Monograph of Basidiophora (Oomycetes) with the description of a new species. Bot. J. Linn. Soc. 107:313-332.

Bourret, T. B., Choundhury, R. A., Mehl, H. K., Blomquist, C. L., McRoberts, N., and Rizzo, D. M. 2018. Multiple origins of downy mildews and mitonuclear discordance within the paraphyletic genus Phytophthora. PLoS ONE 13:e0192502.

Bruisson, S., Maillot, P., Schellenbaum, P., Walter, B., Gindro, K., and Deglène-Benbrahim, L. 2016. Arbuscular mycorrhizal symbiosis stimulates key genes of the phenylpropanoid biosynthesis and stilbenoid production in grapevine leaves in response to downy mildew and grey mould infection. Phytochemistry 131:92-99.

Brundrett, M. C. 2008. Mycorrhizal Associations: The Web Resource. https: $/ /$ mycorrhizas.info.

Brundrett, M. C. 2009. Mycorrhizal associations and other means of nutrition of vascular plants: Understanding the global diversity of host plants by resolving conflicting information and developing reliable means of diagnosis. Plant Soil 320:37-77.

Brundrett, M. C., and Tedersoo, L. 2018. Evolutionary history of mycorrhiza symbioses and global host plant diversity. New Phytol. 220:1108-1115.

Choi, Y.-J., Denchy, C. M., and Shin, H.-D. 2008. Morphological and molecular analyses support the existence of host-specific Peronospora species infecting Chenopodium. Mycopathologia 165:155.

Choi, Y.-J., Kiss, L., Vajna, L., and Shin, H.-D. 2009a. Characterization of a Plasmopara species on Ambrosia artemisiifolia, and notes on $P$. halstedii, based on morphology and multiple gene phylogenies. Mycol. Res. 113:1127-1136.

Choi, Y.-J., Shin, H.-D., and Thines, M. 2009b. Two novel Peronospora species are associated with recent reports of downy mildew on sages. Mycol. Res. 113:1340-1350. 
Choi, Y.-J., Danielsen, S., Lübeck, M., Hong, S.-B., Delhey, R., and Shin, H.-D. 2010. Morphological and molecular characterization of the causal agent of downy mildew on quinoa (Chenopodium quinoa). Mycopathologia 169:403-412.

Choi, Y.-J., Klosterman, S. J., Kummer, V., Voglmayr, H., Shin, H.-D., and Thines, M. 2015. Multi-locus tree and species tree approaches toward resolving a complex clade of downy mildews (Straminipila, Oomycota), including pathogens of beet and spinach. Mol. Phylogenet. Evol. 86:24-34.

Choi, Y.-J., Görg, M., Shin, H.-D., and Thines, M. 2020. Plasmopara elegantissima sp. nov. (Oomycota, Peronosporales), a downy mildew species specialized to Impatiens textori (Balsaminaceae). Mycobiology 48: 304-312.

Constantinescu, O. 1989. Peronospora complex on Compositae. Sydowia 41:79-107.

Constantinescu, O. 1991. An annotated list of Peronospora names. Thunbergia 15:1-110.

Constantinescu, O. 1991. Bremiella sphaerosperma sp. nov. and Plasmopara borreriae comb. nov. Mycologia 83:473-479.

Constantinescu, O. 1992. The nomenclature of Plasmopara parasitic on Umbelliferae. Mycotaxon 43:471-477.

Constantinescu, O. 1998. A revision of Basidiophora (Chromista, Peronosporales). Nova Hedwigia 66:251-265.

Constantinescu, O. 2004. The nomenclature of Plasmopara (Chromista, Peronosporales) parasitic on Geraniaceae. Taxon 53:523-525.

Constantinescu, O., and Fatehi, J. 2002. Peronospora-like fungi (Chromista, Peronosporales) parasitic on Brassicaceae and related hosts. Nova Hedwigia 74:291-338.

Constantinescu, O., Vogelmayr, H., Fatehi, J., and Thines, M. 2005. Plasmoverna gen. nov., and the taxonomy and nomenclature of Plasmopara (Chromista, Peronosporales). Taxon 54:813-821.

Cruz-Silva, A., Figueiredo, A., and Sebastiana, M. 2021. First insights into the effects of mycorrhizae on the expression of pathogen effectors during the infection of grapevine with Plasmopara viticola. Sustainability 13: 1226 .

Cunnington, J. H. 2006. DNA sequence variation supports multiple host-specialised taxa in the Peronospora viciae complex (Chromista: Peronosporales). Nova Hedwigia 82:23-29.

Delaux, P.-M., Varala, K., Edger, P. P., Coruzzi, G. M., Pires, J. C., and Ané, J.-M. 2014. Comparative phylogenomics uncovers the impact of symbiotic associations on host genome evolution. PLoS Genet. 10:e1004487.

Dick, M. W. 2001. Straminipilous Fungi: Systematics of the Peronosporomycetes Including Accounts of the Marine Straminipilous Protists, the Plasmodiophorids and Similar Organisms, 1st Ed. Kluwer Academic Publishers, Dordrecht, The Netherlands.

Farr, D. F., and Rossman, A. Y. 2021. Fungal Databases, U.S. National Fungus Collections, ARS, USDA. https://nt.ars-grin.gov/fungaldatabases/.

Fletcher, K., Gil, J., Bertier, L. D., Kenefick, A., Wood, K. J., Zhang, L., Reyes-Chin-Wo, S., Cavanaugh, K., Tsuchida, C., Wong, J., and Michelmore, R. 2019. Genomic signatures of heterokaryosis in the oomycete pathogen Bremia lactucae. Nature 10:2645.

García-Blázquez, G., Göker, M., Voglmayr, H., Martím, M. P., Tellería, M., and Oberwinkler, F. 2008. Phylogeny of Peronospora, parasitic on Fabaceae, based on ITS sequences. Mycol. Res. 112:502-512.

Göker, M., García-Blázquez, G., Voglmayr, H., Telleria, M. T., and Martin, M. P. 2009b. Molecular taxonomy of phytopathogenic fungi: A case study in Peronospora. PLoS ONE 4:e6319.

Göker, M., Riethmüller, A., Voglmayr, H., Weiß, M., and Oberwinkler, F. 2004. Phylogeny of Hyaloperonospora based on nuclear ribosomal internal transcribed spacer sequences. Mycol. Prog. 3:83-94.

Göker, M., Voglmayr, H., García-Blázquez, G., and Oberwinkler, F. 2009a. Species delimitation in downy mildews: The case of Hyaloperonospora in light of nuclear ribosomal ITS and LSU sequences. Mycol. Res. 113: 308-325.

Göker, M., Voglmayr, H., Riethmüller, A., Weiß, M., and Oberwinkler, F. 2003. Taxonomic aspects of Peronosporaceae inferred from Bayesian molecular phylogenetics. Can. J. Bot. 81:672-683.

Görg, M., Ploch, S., Kruse, J., Kummer, V., Runge, F., Choi, Y.-J., and Thines, M. 2017. Revision of Plasmopara (Oomycota, Peronosporales) parasitic to Impatiens. Mycol. Prog. 16:791-799.

Kadereit, G., Borsch, T., Weising, K., and Freitag, H. 2003. Phylogeny of Amaranthaceae and Chenopodiaceae and the evolution of $\mathrm{C}_{4}$ photosynthesis. Int. J. Plant Sci. 164:959-986.

Kadereit, G., Mavrodiev, E. V., Zacharias, E. H., and Sukhorukov, A. P. 2010. Molecular phylogeny of Atripliceae (Chenopodiodeae, Chenopodiaceae): Implications for systematics, biogeography, flower, and fruit evolution, and the origin of $\mathrm{C}_{4}$ photosynthesis. Am. J. Bot. 97:1664-1687.

McCarthy, C. G. P., and Fitzpatrick, D. A. 2017. Phylogenomic reconstruction of the oomycete phylogeny derived from 37 genomes. mSphere 2: e00095-17.
Neuwirth, E. 2014. RColorBrewer: ColorBrewer Palettes. R package version 1.1-2. https://CRAN.R-project.org/package=RColorBrewer.

Pedersen, T. L. 2021. Patchwork: The composer of plots. https://patchwork data-imaginist.com, https://github.com/thomasp85/patchwork.

Petrželová, I., Choi, Y.-J., Jemelková, M., Doležalová, I., Kruse, J., Thines, M., and Kitner, M. 2017. Confirmation of Peronospora agrimoniae as a distinct species. Eur. J. Plant Pathol. 147:887-896

Pistelli, L., Uliviera, V., Giovanelli, S., Avio, L., Giovannetti M., Pistelli, L. 2017. Arbuscular mycorrhizal fungi alter the content and composition of secondary metabolites in Bituminaria bituminosa L. Plant Biol. 19: 926-933

Quinn, G. P., and Keough, M. J. 2002. Experimental Design and Data Analysis for Biologists. Cambridge University Press, Cambridge, U.K.

R Core Team. 2020. R: A language and environment for statistical computing. R Foundation for Statistical Computing, Vienna, Austria. https://www. R-project.org/.

Ried, M. K., Banhara, A., Hwu, F.-Y., Binder, A., Gust, A. A., Höfle, C., Hückelhoven, R., Nürnberger, T., and Parniske, M. 2019. A set of Arabidopsis genes involved in the accommodation of the downy mildew pathogen Hyaloperonospora arabidopsidis. PLoS Pathog. 15:e1007747.

Riina, R., Peirson, J. A., Geltman, D. V., Molero, J., Frajman, B., Pahlevani, A., Barres, L., Morawetz, J. J., Salmaki, Y., Zarre, S., Kryukov, A., Bruyns, P. V., and Berry, P. E. 2013. A worldwide molecular phylogeny and classification of the leafy spurges, Euphorbia subgenus Esula (Euphorbiaceae). Taxon 62:316-342.

Rivera, Y., Salgado-Salazar, C., Gulya, T. J., and Crouch, J. A. 2016. Newly emerged populations of Plasmopara halstedii infecting Rubeckia exhibit unique genotypic profiles and are distinct from sunflower-infecting strains. Phytopathology 106:752-761.

Rouxel, M., Mestre, P., Baudoin, A., Carisse, O., Delière, L., Ellis, M. A., Gadoury, D., Lu, J., Nita, M., Richard-Cervera, S., Schilder, A., Wise, A., and Delmotte, F. 2014. Geographic distribution of cryptic species of Plasmopara viticola causing downy mildew on wild and cultivated grape in Eastern North America. Phytopathology 104:692-701.

Rouxel, M., Mestre, P., Comont, G., Lehman, B. L., Schilder, A., and Delmotte, F. 2013. Phylogenetic and experimental evidence for hostspecialized cryptic species in a biotrophic oomycete. New Phytol. 197: 251-263.

Runge, F., Choi, Y.-J., and Thines, M. 2011. Phylogenetic investigations in the genus Pseudoperonospora reveal overlooked species and cryptic diversity in the P. cubensis species cluster. Eur. J. Plant Pathol. 129:135-146.

Runge, F., and Thines, M. 2012. Reevaluation of host specificity of the closely related species Pseudoperonospora humuli and P. cubensis. Plant Dis. 96:55-61.

Sage, R. F. 2016. A portrait of the $\mathrm{C}_{4}$ photosynthetic family on the $50^{\text {th }}$ anniversary of its discovery: Species number, evolutionary lineages, and hall of fame. J. Exp. Bot. 67:4039-4056.

Salgado-Salazar, C., LeBlanc, N., Wallace, E. C., Daughtrey, M. L., and Crouch, J. A. 2020. Peronospora monardae, Hyaloperonospora daughtreyae, and H. iberidis: New species associated with downy mildew diseases affecting ornamental plants in the United States. Eur. J. Plant Pathol. 157:311-326.

Shaw, C. G. 1975. The taxonomy of graminicolous downy mildews, with emphasis on those attacking maize. Trop. Res. Ser. 8:47-55.

Spencer, M. A., and Dick, M. W. 2002. Aspects of graminicolous downy mildew biology: Perspectives for tropical plant pathology and Peronosporomycetes phylogeny. Pages 63-81 in: Tropical Mycology, Vol. 2. R. Watling, ed. CABI Publishing, Wallingford, U.K.

Thines, M. 2011. Recent outbreaks of downy mildew on grape ivy (Parthenocisus tricuspidata, Vitaceae) in Germany are caused by a new species of Plasmopara. Mycol. Prog. 10:415-422.

Thines, M. 2014. Phylogeny and evolution of plant pathogenic oomycetes-A global overview. Eur. J. Plant Pathol. 138:431-447.

Thines, M., and Choi, Y.-J. 2016. Evolution, diversity, and taxonomy of the Peronosporaceae, with focus on the genus Peronospora. Phytopathology 106:6-18.

Voglmayr, H., Choi, Y.-J., and Shin, H.-D. 2014a. Multigene phylogeny, taxonomy, and reclassification of Hyaloperonospora on Cardamine. Mycol. Prog. 13:131-144.

Voglmayr, H., Montes-Borrego, M., and Landa, B. B. 2014b. Disentangling Peronospora on Papaver: Phylogenetics, taxonomy nomenclature and host range of downy mildew of opium poppy (Papaver somniferum) and related species. PLoS ONE 9:e96838.

Wang, Y.-Y., Yin, Q.-S., Qu, Y., Li, G.-Z., and Hao L. 2017. Arbuscular mycorrhiza-mediated resistance in tomato against Cladosporium fulvuminduced mould disease. J. Phytopathol. 166:67-74.

Waterhouse, G. M. 1964. The genus Sclerospora: Diagnoses (or descriptions) from the original papers and a key. Comm. Mycol. Inst. Misc. Pub. 17: $1-30$. 
Waterhouse, G. M., and Brothers, M. P. 1981. The taxonomy of Pseudoperonospora. Mycol. Papers 148:1-28.

Wickham, H. 2016. Ggplot2: Elegant graphics for data analysis. SpringerVerlag, New York, NY

Wickham, H., Averick, M., Ryan, J., Chang, W., McGowan, L. D., François, R., Grolemund, G., Hayes, A., Henry, L., Hester, J., Kuhn, M., Pedersen,
T. L., Miller, E., Bache, S. M., Müller, K., Ooms, J., Robinson, D., Seidel, D. P., Spinu, V., Takahashi, K., Vaughn, D., Wilke, C., Woo, K., and Tutani, H. 2019. Welcome to the tidyverse. J. Open Source Software 4:1686.

Yang, Y., and Berry, P. E. 2011. Phylogenetics of the Chamaesyce clade (Euphorbia, Euphorbiaceae): Reticulate evolution and long-distance dispersal in a prominent $\mathrm{C}_{4}$ lineage. Am. J. Bot. 98:1486-1503. 